\title{
Análise editorial e gráfica da revista Atualidades Capixabas
}

\author{
Editorial and graphic analysis of magazine Atualidades Capixabas
}

Rayani Furlani Muller, Letícia Pedruzzi Fonseca

revistas capixabas. década de 1950. análise gráfica. história do design no Espírito Santo.

Este artigo apresenta a análise editorial e gráfica da revista Atualidades Capixabas, cuja publicação ocorreu entre os anos de 1950 e 1951, na cidade de Vitória. A publicação ficava a cargo do Departamento de Estatística do Estado do Espírito Santo e objetivava a propagação da cultura capixaba e a divulgação de obras públicas. Para a pesquisa, foi utilizado o "Conjunto Metodológico para Pesquisa em História do Design a partir de Materiais Impressos" (Fonseca et al, 2016). Os resultados mostraram que as estratégias de planejamento e configuração da revista davam destaque a apresentação do Estado tendo a fotografia como linguagem primordial. Essa pesquisa faz parte de um desdobramento do inventário das Revistas Capixabas, que tem como intuito, trazer à luz dados inéditos sobre as publicações e contribuir com a construção da memória gráfica capixaba.

capixabas magazines. 1950s. graphical analysis. history of design in Espírito Santo.

This article presents the editorial and graphic analysis of the magazine Atualidades Capixabas, which was published between 1950 and 1951, in the city of Vitória. The publication was under the responsibility of the Department of Statistics of the State of Espirito Santo and had the objective of spreading the culture of the state and public works. For the research, the "Methodological Series for Research in Design History from Printed Materials" (Fonseca et al, 2016) was used. The results showed that the planning and configuration strategies of the magazine emphasized the presentation of the State, with photography as the primary language. This research is part of an unfolding of the inventory of the Capixabas Magazines, which aims to bring to light new original data about publications and contribute to the construction of the graphic memory of Capixaba.

\section{Introdução}

A partir do inventário de revistas capixabas que identificou e registrou dados de mais de 300 revistas em acervos públicos da Região da Grande Vitória (Matos et al, 2019), foi iniciada uma pesquisa a respeito das publicações nas décadas de 1940 e 1950.

Este artigo objetiva apresentar a revista Atualidades Capixabas tendo como preceito o design da informação, "cujo propósito é a definição, planejamento e configuração de uma mensagem, com a intenção de satisfazer as necessidades informacionais dos destinatários pretendidos e de promover eficiência comunicativa" (SBDI, 2020), por meio de aferições de diferentes aspectos de sua anatomia gráfica e correlacionar os resultados com o contexto sócio-histórico.

Anais do $10^{\circ} \mathrm{CIDI}$ e $10^{\circ} \mathrm{CONGIC}$

Kelli C.A.S. Smythe, Rafael de Castro Andrade (orgs.)

Sociedade Brasileira de Design da Informação - SBDI

Curitiba | Brasil | 2021
Proceedings of the $10^{\text {th }} \mathrm{CIDI}$ and $10^{\text {th }}$ CONGIC

Kelli C.A.S. Smythe, Rafael de Castro Andrade (orgs.)

Sociedade Brasileira de Design da Informação - SBDI Curitiba | Brazil | 2021 


\section{Metodologia}

Para o estudo, temos como base o "Conjunto Metodológico para Pesquisa em História do Design a partir de Materiais Impressos" (Fonseca et al, 2016), que propõe duas frentes de trabalhos paralelas. A primeira, que prevê a aproximação do pesquisador com o contexto sóciohistórico do impresso, compreendeu a revisão bibliográfica sobre o período estudado. A segunda etapa consistiu na análise gráfica do impresso e para tanto foi necessária a identificação de acervos, registro fotográfico, organização do acervo digital, coleta de dados, análise e discussão dos resultados.

Os parâmetros estabelecidos para a análise foram: título, equipe da revista; tipologia; preço, periodicidade; formato; edições especiais; elementos gráficos; variação cromática; parque gráfico e cidade (Matos et al, 2019).

Cabe ressaltar que a revista será estudada como objeto de pesquisa e também como fonte (Luca, 2005), pois muitas informações puderam ser aferidas com a análise do conteúdo editorial.

Exemplares da revista podem ser encontrados em duas bibliotecas públicas, a saber: Arquivo Público do Espírito Santo (APEES), cujo acervo está completo com todas as edições e, na Biblioteca Pública do Espírito Santo (BPES), apenas a edição especial.

\section{Desenvolvimento}

A revista Atualidades Capixabas foi lançada em 1950 na cidade de Vitória, era produzida pelo Departamento de Estatística do Estado do Espírito Santo e teve como apoio, tanto o Governo Estadual, como o Foto Clube de Vitória, que disponibilizou os direitos de imagens das fotografias que ilustram a revista (Atualidades Capixabas, $1951, n^{\circ} 5, p .1$ ). Com periodicidade trimestral, o último número que se tem registro é da edição dupla (6/7), comemorativa do IV Centenário de Vitória.

A revista abordava tanto temáticas da capital, quanto informações sobre a cultura do Espírito Santo, com uma coluna fixa de apresentação de um município por edição, além de assuntos relacionados à educação e agricultura. Seu formato é de $23 \times 15,5 \mathrm{~cm}$, não continha anúncios e não há menção acerca de seu valor monetário. Mas, no texto em comemoração ao primeiro aniversário de publicação da revista, afirmou que o número de assinantes crescia constantemente e que, inclusive, a tiragem da primeira edição havia esgotado (Atualidades Capixabas, $1951, n^{\circ} 5$, p. 1).

A equipe responsável por sua publicação era formada por: Antônio Lugon (Diretor) e José do Patrocínio M. de Oliveira (Redator Chefe).

A ideia para a publicação do periódico surge da necessidade de retornar com um folhetim do Departamento de Estatística (Atualidades Capixabas, 1950, $n^{\circ}$ 1, p. 1). E, para tal, a revista contava com um recurso inovador para o período, diferente das revistas capixabas antecessoras, a revista apresentava uma série de fotografias de monumentos capixabas ou de ângulos das cidades, de forma a ilustrar os textos e de publicizar diferentes locais do Estado. A publicação também pode ser vista como meio de divulgação das obras públicas estaduais 
que vinham sendo implementadas. Vale lembrar que o governador estadual do período era Jones dos Santos Neves, responsável por projetos desenvolvimentistas, previstos em seu Plano de Valorização Econômica do Espírito Santo (Vasconcellos, 1995).

\section{Capa}

A configuração da capa não foi alterada ao longo de suas seis publicações. O nome da revista era alinhado dentro de um retângulo horizontal, ora azul, ora vermelho. O título era composto em um lettering exclusivo, com características geométricas e, com a remoção do travessão da letra "A", dando identidade à assinatura da revista. Além disso, as letras são vazadas nesse box colorido. É importante destacar que esse elemento é o único na revista que contém cor.

Figura 1: Assinatura da revista. Fonte: Acervo digital do LadHT (2021).

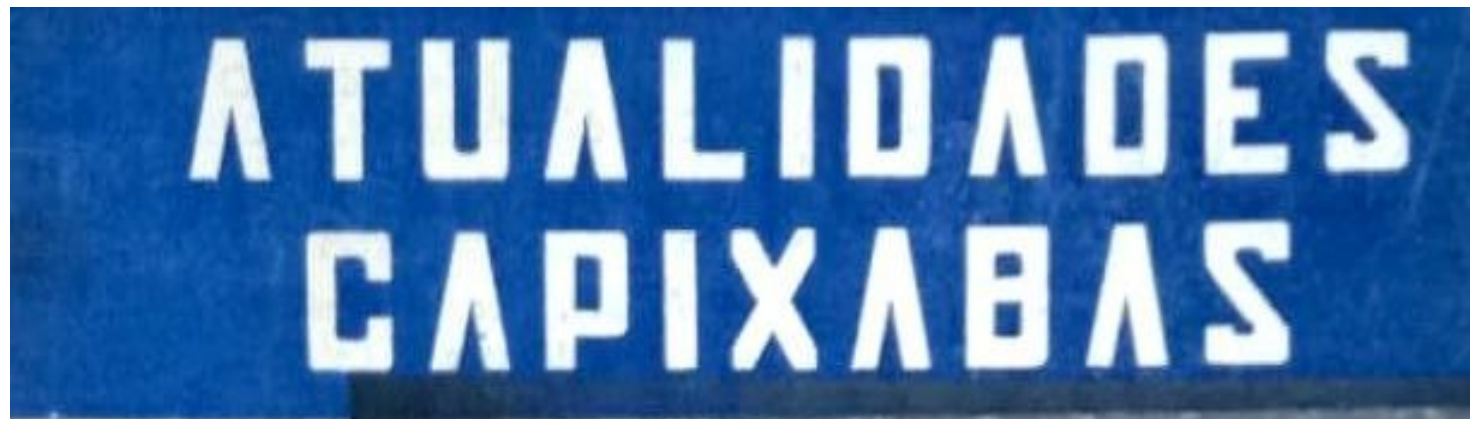

As demais informações foram setorizadas, de forma a dar mais destaque para a fotografia de capa.

Figura 2: Capas da revista. Fonte: Acervo digital do LadHT (2021).
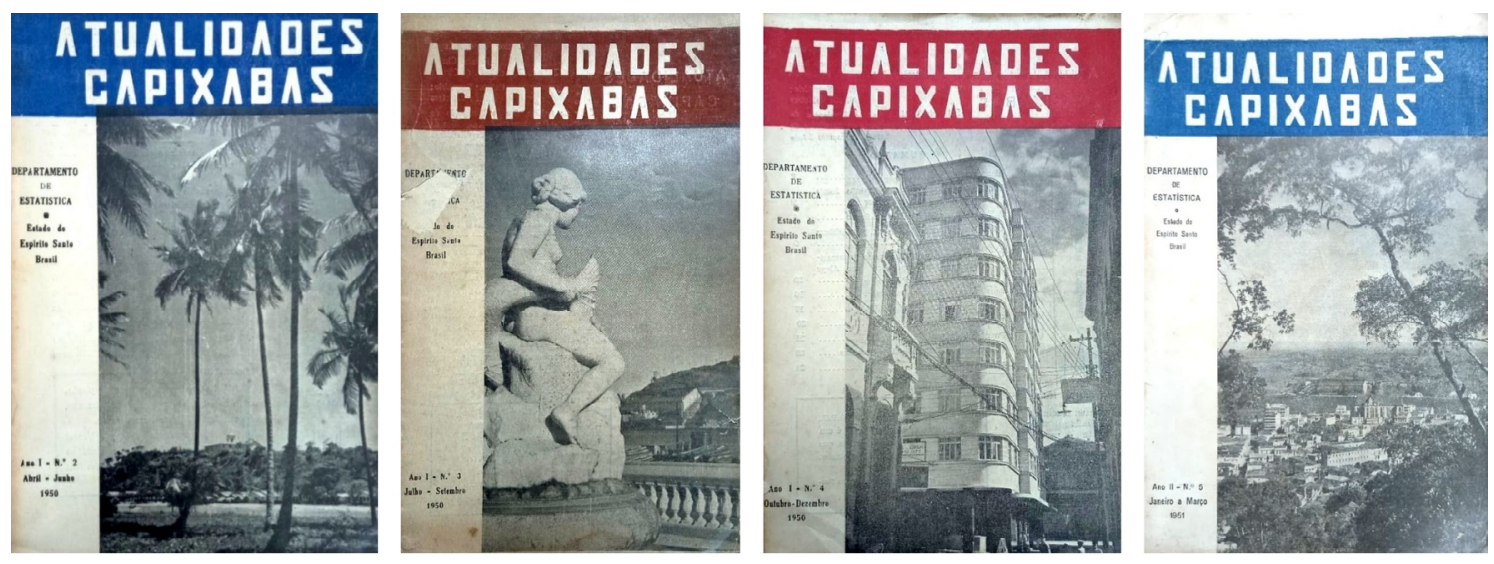

\section{Miolo e imagens}

O miolo da revista não apresenta grandes soluções gráficas. É possível perceber que com o passar das edições, o número de fotografias por edição foi aumentando, bem como as possibilidades de sua disposição na página. 
Foi utilizada uma única família tipográfica em todas as edições para o corpo do texto, com tamanhos alternados conforme o espaço destinado para determinada matéria. É importante destacar que para os títulos eram utilizadas outras famílias tipográficas, majoritariamente sem serifa, em alguns casos, com peso bold.

Quanto ao uso de colunas, o texto era disposto tanto em uma única coluna, quanto em duas colunas. Além disso, os parágrafos eram demarcados por meio de um recuo na primeira linha e, alguns textos escritos em apenas uma coluna, não necessariamente seguem as margens da mancha gráfica (Figura 3).

Figura 3: Disposição do texto em colunas. Fonte: Acervo digital do LadHT (2021).

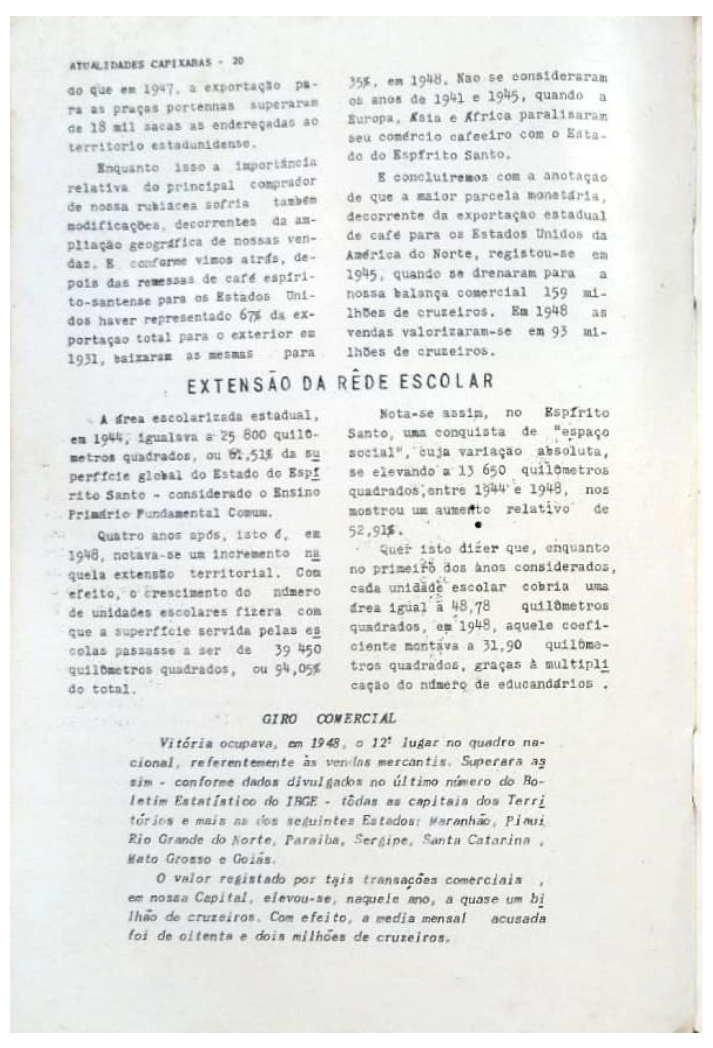

Na segunda edição apresenta características únicas. O uso de um olho em uma reportagem (Figura 4), denotando a experimentação de um recurso moderno de destaque de parte do texto, e também o uso de um gráfico ilustrado (Figura 5), a informação visual dando suporte e mediando a apresentação dos dados. 
Figura 4: Olho de uma matéria. Fonte: Acervo digital do LadHT (2021).

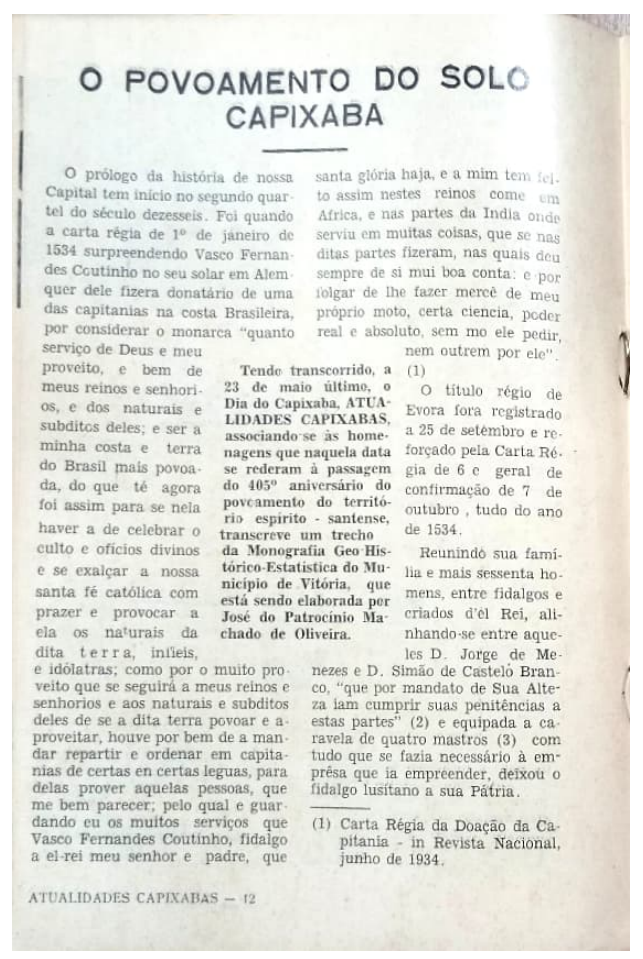

Figura 5: Gráfico llustrado. Fonte: Acervo digital do LadHT (2021).

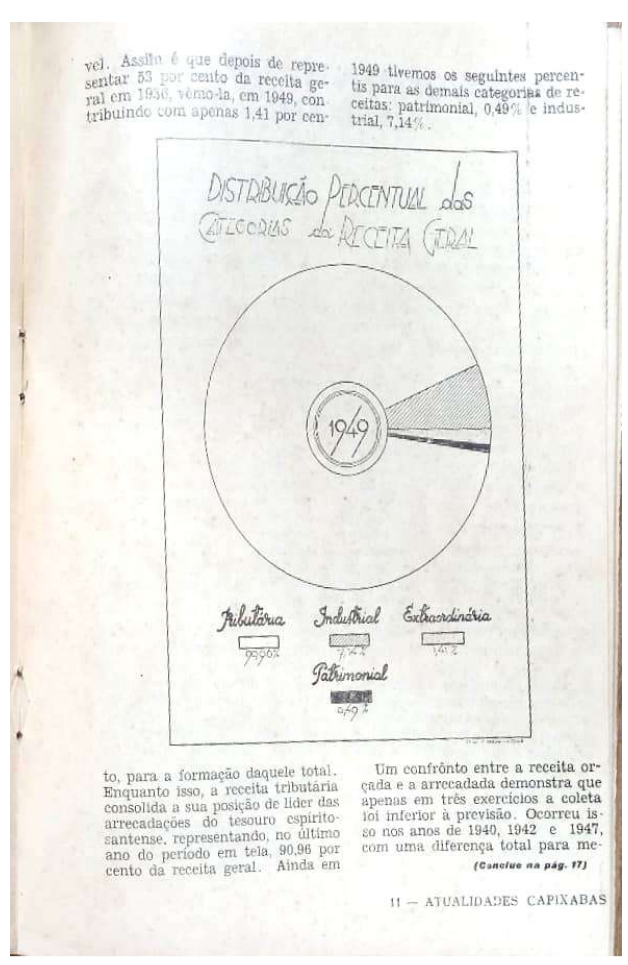

A quarta capa era um espaço destinado à fotografia de algum ponto turístico do Espírito Santo. Para melhor aproveitamento da página dando destaque à fotografia, a orientação de leitura era rotacionada para uma orientação em modo paisagem. A imagem era acompanhada por uma legenda informando o local de destaque da fotografia e o responsável pelo registro (Figura 6). 
Figura 6: Quartas capas. Fonte: Acervo digital do LadHT (2021).
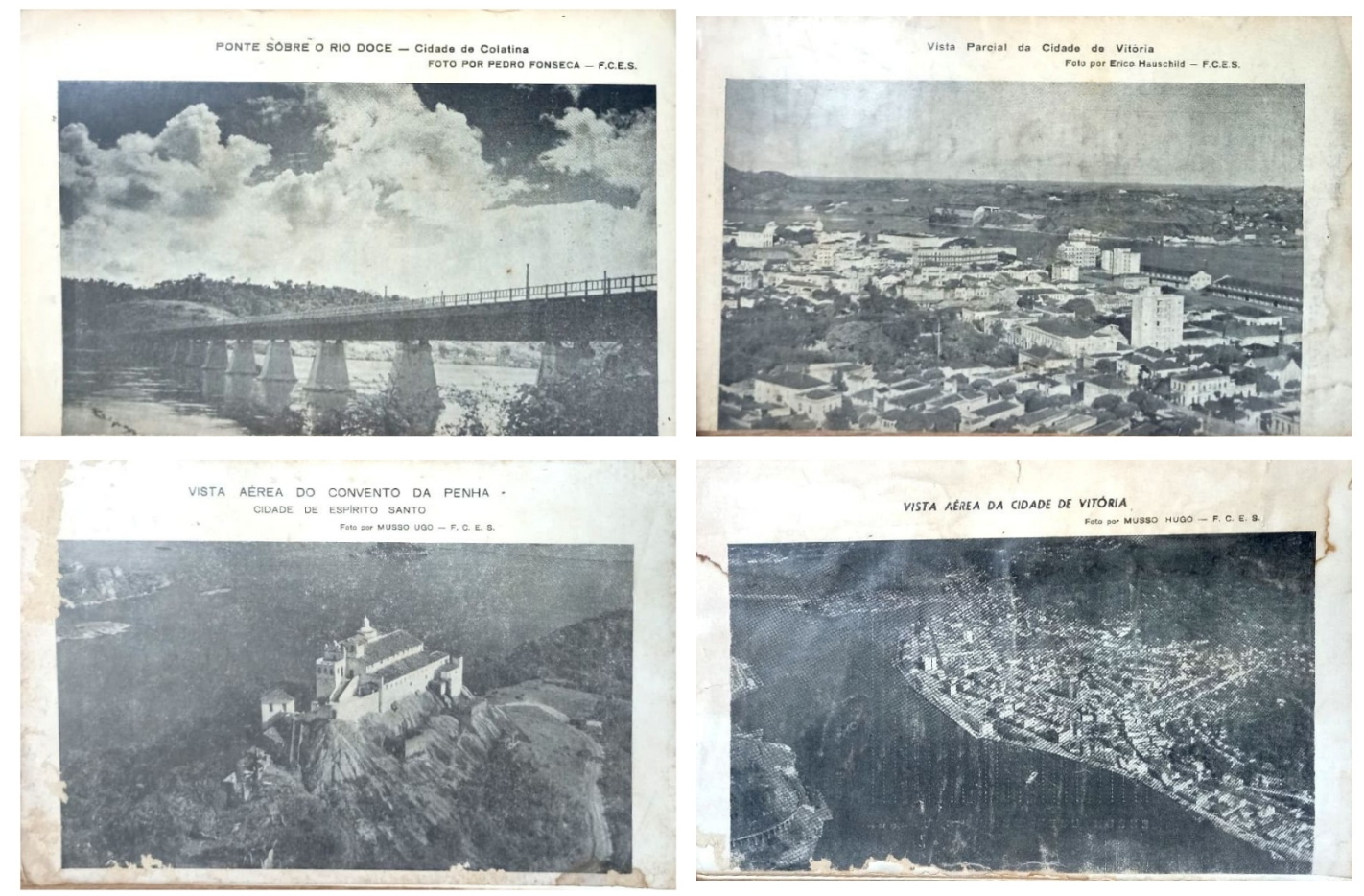

Para a edição comemorativa do IV Centenário de Vitória, ocorreram algumas alterações na configuração visual da revista. Além disso, o número de páginas mais que dobrou se comparado com as primeiras.

Diferentemente das edições anteriores, que foram impressas no parque gráfico da Vida Capichaba, esta foi impressa na "Pap. Samorin - Moacyr Barbosa \& Cia LTDA". Na edição comemorativa, a revista agradece os esforços do parque gráfico da Vida Capichaba:

As dificuldades de impressão têm sido vencidas pela dedicação do pessoal da "Vida Capichaba", em cujas oficinas foram impressos os 4 números de 1950, o qual lutando com a falta de material adequado, tudo tem feito no sentido de superar esse obstáculo e apresentar o melhor trabalho possível (Atualidades Capixabas, 1951, $n^{\circ} 5$, p. 1).

Essa citação destaca o esforço empenhado na produção da revista, que conseguiu manter sua circulação mesmo durante a crise de escassez nacional da produção de papel, tendo seus motivos associados ao período da campanha eleitoral (Boletim da Indústria Gráfica, 1950, $n^{\circ} 25$, capa).

Também pode-se averiguar o destaque dado aos políticos por meio da composição de fotografias em ordem hierárquica do Presidente da República, do Governador Estadual e do Prefeito Municipal da época.

Nesta edição é possível ver um título escrito em lettering, assim como com uma página exclusiva para uma única fotografia com três margens sangradas (Figuras 7 e 8). 
Figura 7: Lettering exclusivo para o título de uma matéria. Fonte: Acervo digital do LadHT (2021).

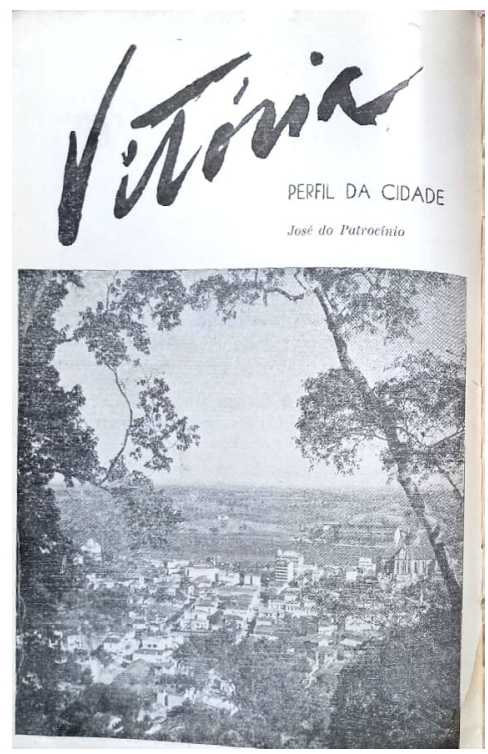

Figura 8: Fotografia em destaque sangrando em três lados da folha.

Fonte: Acervo digital do LadHT (2021).

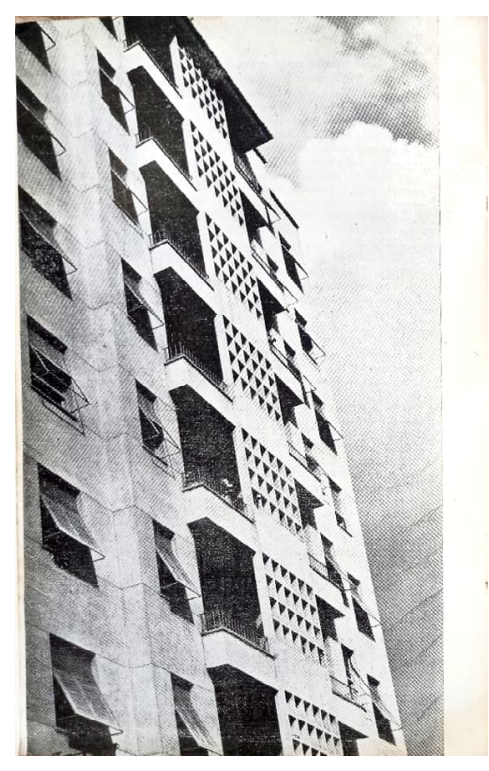

\section{Resultados}

Em relação ao conteúdo editorial, observou-se que os conteúdos da revista eram diversos, abordando diferentes temáticas sobre o desenvolvimento do Estado em diferentes setores.

Mas, em comum, cada edição apresenta reportagens que abordam a temática da educação e agricultura. Além da descrição de um município e uma coluna que recebeu o título de "várias notícias", com notas rápidas sobre temas variados, que pode ser comparada com seções da revista "Vida Capichaba"

Da mesma forma, quando aborda assuntos rurais e agrícolas, parecendo uma versão resumida da revista "Agricultura Capixaba", ou quando menciona sobre a educação estadual, que era o mote da "Revista de Educação"; o fato de tecer homenagens a municípios capixabas, 
assunto que motivou a publicação de "Cachoeiro de Itapemirim - um município numa revista". Esse destaque mostra os assuntos recorrentes na imprensa capixaba da época e corrobora com o fato de ser uma revista com um vasto leque de abordagens.

Já em relação a análise gráfica, foi identificada uma identidade visual própria. As cinco capas não sofreram modificações quanto a sua estrutura e apresentavam letras desenhadas exclusivamente para a assinatura da revista. Nas capas, a única mudança notada foi da cor azul para a cor vermelha.

O miolo da revista era monocromático e uma única tipografia com serifa foi utilizada no corpo dos textos. Os destaques eram dados aos títulos, por meio da escolha de outra tipografia e maior peso visual.

Sem menções quanto ao seu valor monetário e sem referências de anunciantes, pelo caráter de suas temáticas, podemos classificá-la como um instrumento moderno e persuasivo do governo estadual, por meio de seu departamento de estatística.

\section{Considerações Finais}

Pode-se concluir que a Atualidades Capixabas foi uma revista de variedades com forte influência do contexto político da época, até por ser uma publicação de um departamento do governo estadual.

A análise gráfica demonstrou o investimento na linguagem fotográfica para ilustrar as matérias e nas experimentações relacionadas às composições visuais de suas páginas. Dessa maneira, a revista se destacava pelo apelo visual proporcionado pelo aumento do uso de fotografias e em como elas compunham a configuração gráfica, pelo papel em que era impressa e por suas experimentações com o uso de olho e de gráficos.

A pesquisa sobre a revista Atualidades Capixabas permitiu apresentar e detalhar as características editoriais e gráficas de uma revista capixaba até então desconhecida e suas estratégias informacionais por meio da apresentação do conteúdo de suas páginas. Além disso, faz parte dos estudos focados na memória gráfica capixaba, que pretende trazer à luz novos artefatos que constituem nossa história gráfica e informacional.

\section{Referências}

Atualidades Capixabas (1950), Vitória, n¹, janeiro a março 1950.

Atualidades Capixabas (1951), Vitória, n5, janeiro a março 1951.

Boletim da Indústria Gráfica (1950), São Paulo, n 25, 2ª quinzena de novembro de 1950.

Fonseca, L.P., Gomes, D.D. \& Campos, A.P. (2016). Conjunto Metodológico para Pesquisa em História do Design a partir de Materiais Impressos. Revista Brasileira de Design da Informação, v. 13, n. 2, p. 143-161.

Luca, T.R. (2005) de. História dos, nos e por meio dos periódicos. In: PINSKY, Carla Bassanezi (org.). Fontes históricas. São Paulo: Contexto, p. 111-153. 
Matos, T.K., Santos, N.M., Nascimento, B.B., Fonseca, P. L. (2019). Metodologia para inventário de revistas. Revista Brasileira de Design da Informação, São Paulo, v. 16, n. 3, p. 456-466.

Sociedade Brasileira de Design da Informação (SBDI). Brasil, 2020. Disponível em: <http://www.sbdi.org.br/definicoes>. Acesso em: 19 jul. 2021.

Vasconcellos, J.M. (1995). A invenção do Coronel: ensaio sobre as raízes do imaginário político brasileiro. Vitória: SPDC.

\section{Sobre as autoras}

Rayani Furlani Muller, graduanda, Ufes, Brasil <rayanimuller@hotmail.com> Letícia Peduzzi Fonseca, Dra, Ufes, Brasil <leticia.fonseca@ufes.br> 